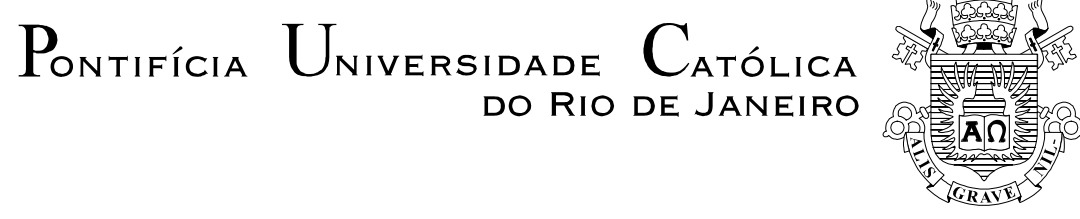

Felipe Gomberg

\title{
A aura do livro na era de sua reprodutibilidade técnica
}

Dissertação de Mestrado

Dissertação apresentada como requisito parcial para obtenção do grau de Mestre pelo Programa de Pósgraduação em Comunicação Social do Departamento de Comunicação da PUC-Rio.

Orientadora: Profa. Vera Lúcia Follain de Figueiredo

Rio de Janeiro

Março de 2006 


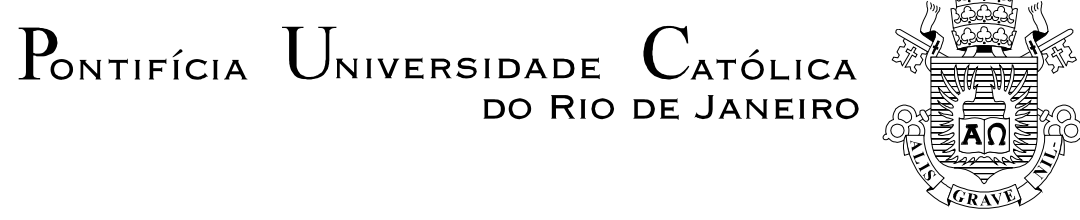

Felipe Gomberg

\section{A aura do livro na era de sua reprodutibilidade técnica}

Dissertação apresentada como requisito parcial para obtenção do grau de Mestre pelo Programa de PósGraduação em Comunicação Social do Departamento de Comunicação Social do Centro de Ciências Sociais da PUC-Rio. Aprovada pela Comissão Examinadora abaixo assinada.

Profa. Vera Lúcia Follain de Figueiredo Departamento de Comunicação Social - PUC-Rio

Prof. José Carlos de Souza Rodrigues Departamento de Comunicação Social - PUC-Rio

Profa. Sandra Lúcia Amaral de Assis Reimão UMESP

Prof. João Pontes Nogueira Vice-Decano de Pós-Graduação do CCS 
Todos os direitos reservados. É proibida a reprodução total ou parcial do trabalho sem autorização do autor, da orientadora e da universidade.

\section{Felipe Gomberg}

Graduou-se em Comunicação Social, com habilitação em Jornalismo na PUC-Rio. Cursou pós-graduação lato sensu, MBA em Marketing, no IAG/PUC-Rio. Atualmente é professor do Departamento de Comunicação Social da PUC-Rio e assistente de edição da PUC-Rio.

Ficha Catalográfica

Gomberg, Felipe

A aura do livro na era de sua reprodutibilidade técnica / Felipe Gomberg ; orientadora: Vera Lúcia Follain de Figueiredo. - Rio de Janeiro : PUC, Departamento de Comunicação, 2006.

120 f. ; $30 \mathrm{~cm}$

Dissertação (mestrado) - Pontifícia Universidade Católica do Rio de Janeiro, Departamento de Comunicação.

Inclui referências bibliográficas.

1. Comunicação - Teses. 2. Livro impresso. 3. Escrita. 4. História do livro. 5. Indústria cultural. 6. Mercado editorial. I. Figueiredo, Vera Lúcia Follain de. II. Pontifícia Universidade Católica do Rio de Janeiro. Departamento de Comunicação. III. Título. 


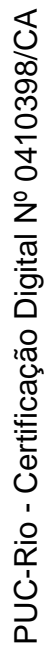

Ao meu querido avô, Jayme Rosenthal, que deixará saudades para sempre. 


\section{Agradecimentos}

Aos meus pais, José Elias e Miriam, por tudo, inclusive por terem permitido que eu chegasse até aqui.

À minha irmã, Evelyn, leitora e revisora não-oficial do texto.

A Giovana, pelo amor e apoio de sempre.

À minha orientadora, professora Vera Follain, pela dedicação, carinho e paciência comigo e com meu trabalho.

A Fernando Sá, pelas aulas diárias sobre o "negócio do livro”, pela troca de idéias e pelo incentivo.

A todos os meus amigos que me apoiaram nessa jornada.

Aos professores do Programa de Pós-graduação em Comunicação Social.

Ao professor Renato Cordeiro Gomes, coordenador do Programa de Pósgraduação em Comunicação Social.

À Secretaria do Programa de Pós-graduação em Comunicação Social. 
Ao lermos um livro antigo, é como se o estivéssemos lendo ao longo de todo o tempo que transcorreu até nós desde o dia em que foi escrito. Por isso, convém manter o culto ao livro. Nele pode haver muitas erratas, podemos não estar de acordo com as opiniões do autor. Ainda assim, porém, o livro conserva algo de divino, não implicando um respeito supersticioso, mas o desejo de encontrar felicidade, de encontrar sabedoria.

Jorge Luis Borges, O livro 


\section{Resumo}

Gomberg, Felipe; Figueiredo, Vera Lúcia Follain de (Orientadora). A aura do livro na era de sua reprodutibilidade técnica. Rio de Janeiro, 2006. 120p. Dissertação de Mestrado - Departamento de Comunicação Social, Pontifícia Universidade Católica do Rio de Janeiro.

Com a reprodutibilidade técnica, segundo Walter Benjamin, a obra de arte, ao aproximar-se do humano, sendo difundida em inúmeras cópias circulantes, perderia o caráter único que a distinguia na sua sacralidade pré-industrial, isto é, perderia a aura. A hipótese deste trabalho é a de que o livro impresso, apesar de ser um produto da indústria cultural, preservaria ainda hoje algo dessa aura de que nos fala Benjamin, como um traço remanescente de sua longa história. Nesse sentido, faz-se um recuo no tempo, partindo-se da preeminência da escrita na cultura ocidental como fato fundamental no processo de auratização do livro, com o objetivo de refletir sobre as possíveis razões da sobrevivência de seu prestígio como meio de comunicação e como produto cultural no início do século XXI, isto é, numa época caracterizada pela revolução comunicacional gerada pelo avanço dos meios eletrônicos e digitais.

\section{Palavras-chave}

Livro impresso; escrita; história do livro; indústria cultural; mercado editorial. 


\section{Abstract}

Gomberg, Felipe; Figueiredo, Vera Lúcia Follain de (Advisor). The aura of the book in the age of its mechanical reproduction. Rio de Janeiro, 2006. 120p. MSc. Dissertation - Departamento de Comunicação Social, Pontifícia Universidade Católica do Rio de Janeiro.

According to Walter Benjamin, with the mechanical reproduction, work of art has came near to the human being, loosing its aura - the sacred uniqueness of the objects that distinguish themselves in pre-industrial society. The hypotesis of this written essay is that the printed book, although being a industrial culture product, could preserve something of this aura, that Benjamin told us about, as a remaining vestige of the book's long history. In this sense, we come back on time line, starting on the pre-eminence of the writing on the occidental culture as a fundamental fact to the process of book's auratização, with the objective of reflect about the possible reasons of the survival of its prestige as a media and as a cultural product in the beginning of the $21^{\text {st }}$ century, that is, in a period characterized by a communicational revolution generated on the advances of electronic and digital media.

\section{Keywords}

Printed book; writting; book’s history; cultural industry; book’s market. 


\section{Sumário}

$\begin{array}{ll}\text { 1. Introdução } & 10\end{array}$

2. A preeminência da escrita na cultura ocidental 23

2.1. E surge a escrita... $\quad 24$

2.2. A opção pela escrita $\quad 29$

2.3. A escrita por meio do alfabeto 33

2.4. A escrita como pharmacón 37

2.5. Da oralidade à escrita: alguns atalhos 41

2.5.1. A sociedade da oralidade primária 43

2.5.2. A sociedade da oralidade mista $\quad 47$

3. A auratização moderna do livro 54

3.1. A ascensão de uma nova classe de "homens de letras" 62

3.2. A Enciclopédia $\quad 67$

3.3. As bibliotecas $\quad 71$

3.4. Livro e poder $\quad 73$

3.5. O homem moderno e o livro 75

4. O mercado editorial e a aura do livro 82

4.1. As editoras de livros $\quad 84$

4.2. O ritual da noite de autógrafos: o "batizado" 92

4.3. Como os livros são consumidos 95

4.4. O livro nos meios de comunicação: no jornal, no cinema, na TV e na internet 101

$\begin{array}{ll}\text { 5. Conclusão } & 111\end{array}$

6. Referências bibliográficas 117 